\title{
Crianças vivendo com HIV e Casas de Apoio em São Paulo: cultura, experiências e contexto domiciliar*
}

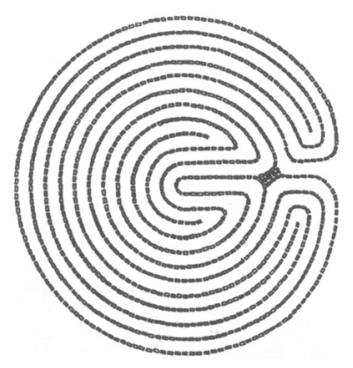

César Ernesto Abadia-Barrero 1

ABADÍA-BARRERO, C. E. Children living with HIV and Support Homes in São Paulo: culture, experiences and housing context, Interface - Comunic, Saúde, Educ, v.6, n.11, p.55-70, 2002.

This article, based on research in the field of Medical Anthropology, intends to analyze certain cultural factors that play a role in the development of children and adolescents with HIV in support homes. There are similarities and differences in the child rearing patterns of each institution and, consequently, in the individual and social development of the children and adolescents. One notable similarity is, nonetheless, that the improvement in the quality of life and life expectancy (with many children becoming adolescents) seems to have become a problem for their adult caretakers. I try to explain how this problem is largely due to the ideas and the image of what a child with Aids in Brazil represents. These ideas are culturally constructed and follow modern categories and discussions concerning childhood, development and morally acceptable social responses. The development of children and adolescents with HIV/Aids argues against these categories and threatens the child rearing patterns established by the adults on the one hand and by the structure of the institutions on the other.

KEYWORDS: Children; adolescence; HIV; recovery homes; culture.

Este artigo, baseado em pesquisa na área da Antropologia Médica, pretende analisar alguns fatores culturais que influem no desenvolvimento de crianças e adolescentes vivendo com HIV em casas de apoio. Existem semelhanças $e$ diferenças nos padrões de criação de cada instituição e, em conseqüência, no desenvolvimento individual e social das crianças e adolescentes. Uma semelhança marcante é que a melhora na qualidade de vida e o aumento da sobrevida (com muitos virando adolescentes) parece ter-se convertido em um problema para os adultos que cuidam deles. Minha intenção é explicar como este problema deve-se, em grande parte, às idéias e ao imaginário do que a criança com Aids no Brasil representa. Essas idéias são culturalmente construídas e estão em sincronia com as categorias e discussões modernas sobre criança, desenvolvimento e respostas sociais moralmente aceitáveis. O desenvolvimento de crianças e adolescentes vivendo com HIV/Aids questiona as ditas categorias ameaçando, inclusive, os padrões de criação estabelecidos pelos adultos e as estruturas das instituições.

PALAVRAS-CHAVE: Criança; adolescência; HIV; casas para recuperação; cultura.

* Esta pesquisa faz parte do meu doutorado na Universidade de Harvard e do estágio como pesquisador junto ao Departamento de Medicina Preventiva da Universidade de São Paulo. Agradeço ao Professor José Ricardo Ayres pela sua orientação durante a pesquisa e pela edição do presente texto; aos presidentes das duas casas, Laércio Zaniquelli, no caso do CCI "Filhos de Oxum", e Padre Valeriano Paittoni, na casa Siloé, que sempre se ofereceram para fornecer a ajuda necessária para a pesquisa. Além deles, todos os funcionários, crianças e adolescentes, meus amigos nesta jornada, com quem compreendi a importância das emoções como detonantes da razão.

${ }^{1}$ Doutorando em Antropologia Médica, Harvard University. <cesar_abadia@hms.harvard.edu> 


\author{
Roberta (6 anos), \\ brincando com bonecas, respondeu à minha pergunta: \\ você vai ter filhos? Aha!!. \\ E você vai cuidar deles? Não, a empregada!
}

Quando comecei meu trabalho de pesquisa em Antropologia Médica no Brasil $^{2}$, percebi que as idéias que trazia sobre a vida de crianças com HIV/ AIDS estavam muito distantes da realidade. Tinha aprendido, pelas pesquisas das áreas de Biologia, de Epidemiologia e algumas pesquisas sociais, que limitações fisicas, doença e certeza de morte deveriam ser eventos dominantes na vida de crianças infectadas pelo HIV. Porém, quando iniciei o trabalho, percebi que esses referenciais eram parte do passado $e$ temor constante para os adultos, mas sequer passavam pelos discursos cotidianos das crianças. Como conseqüência da Aids, crianças e adolescentes moravam em instituições nas quais eu estava trabalhando (casas de apoio de organizações não governamentais - ONG(Aids -) e que a maioria era órfã. Todavia, analisando as histórias de vida das famílias (pelos relatórios do juizado e entrevistas com os cuidadores atuais) notei que a desintegração do núcleo familiar devia-se não somente à Aids, mas também à pobreza, vida em favela, migração, ao tráfico e consumo de drogas, à morte violenta e incapacidade de cuidar dos próprios filhos. Ou seja, a Aids fazia parte de um universo maior de fatores condicionantes da desintegração familiar e não podia ser considerada como única causa ${ }^{3}$.

Por outro lado, o sentir-se doente ou estar limitado fisicamente tinha deixado de ser a característica mais dominante na vida das crianças. Devido à implementação da terapia antiretroviral (ARV) para o tratamento da infecção pelo HIV/AIDS em 1996, não só houve uma diminuição significativa do número de mortes, como também das chamadas doenças oportunistas melhorando, portanto, a sobrevida e a qualidade de vida dos portadores. Sob a perspectiva das crianças, esta melhoria tem significado a possibilidade de ter vidas "normais", chegar à adolescência e pensar em desenvolvimento e futuro. No momento atual, raras vezes as crianças e os adolescentes pensam em doença, limitação ou morte como condicionantes de suas vidas; não teriam porque fazê-lo ${ }^{4}$. O fato de haver tantos adolescentes que nasceram infectados me obrigou, inclusive, a mudar a forma de denominar a pesquisa, que passava, então, de crianças com Aids para crianças e adolescentes com Aids. Por outro lado, necessitava entender por que se continuava falando das crianças com Aids e pouco de adolescentes e por que se insistia em diferenciar as crianças com Aids dos adultos com Aids, como se pertencessem a duas epidemias diferentes, ou a dois mundos diferentes.

Depois de perceber a condição "saudável" das crianças e dos adolescentes, a forma como a epidemia tinha mudado depois da chegada da medicação antiretroviral e de meus primeiros dados das conversações e brincadeiras que compartia com eles, entendi que minha pesquisa teria que considerar não só como a Aids influenciava a vida das crianças de forma direta pela soropositividade, mas também como a influenciava indiretamente pela forma como os adultos $e$ instituições se relacionavam com as crianças
${ }^{2}$ A Antropologia Médica é, em resumo, um ramo aplicado da Antropologia Social que estuda as conexões entre os fatores biológicos e culturais da saúde e da doença.

${ }^{3}$ Ver Farmer, P., M. Connors, et al., Eds. (1996) e Farmer, $P$. (1999) para uma análise maior dos determinantes sociais na AIDS. Farmer cita a desigualdade social como determinante principal para que a aids se espalhe em camadas pobres da população. Para uma revisão da ligação pobreza-AIDS no Brasil, ver Bastos \& Szwarcwald (2000) e Parker \& Rochel (2000).

${ }^{4}$ As vidas das crianças e dos adolescentes soropositivos no Brasil exemplificam o resultado de políticas em saúde adequadas e participação da sociedade civil em um pais considerado em desenvolvimento. No mundo estima-se que 1.3 milhões de criançase

adolescentes têm HIV mas só menos de 5\% recebem tratamento adequado. Para uma análise da trajetória da luta do Brasil, ver Galvão (2000). 
soropositivas. Desse modo, tão importante quanto analisar o relacionamento criança-Aids, era também a análise dos relacionamentos adulto-Aids, instituição-Aids, adulto-criança $e$ instituição-criança. Agora, minha tarefa mais ampla era entender como as experiências de vida de crianças e adolescentes com AIDS estavam informadas pelos múltiplos relacionamentos com os adultos $e$ as instituições no Brasil de hoje.

Comecei a perceber que, para os adultos, aquelas referências históricas da epidemia do passado (limitações físicas, doença e expectativa de morte) continuavam fazendo parte da forma como caracterizavam o presente e, como conseqüência, da forma como os adultos $e$ as instituições se relacionavam com as crianças e os adolescentes. Percebi como adultos, adolescentes e crianças tinham posições diferentes perante a vida, inclusive, perante o significado de ser criança e ter Aids. Neste texto, pretendo expor essas diferenças e entender o momento histórico que permite compreendê-las. Pretendo, também, expor as ligações das experiências das crianças com Aids com as idéias modernas de infância e seus significados, e como a idéia criança e Aids no Brasil é um exemplo das construções culturais típicas da modernidade.

\section{Dados da pesquisa etnográfica}

Os dados aqui apresentados fazem parte do trabalho de campo desenvolvido entre Outubro 1999 e Julho 2001. Participei, como voluntário, em atividades diárias com crianças e adolescentes em duas casas de apoio de ONG/Aids, uma creche (ONG/Aids) e o abrigo estadual para meninos em situação de rua Moóca. Meus dados fundamentaram-se em entrevistas informais semiestruturadas, conversações cotidianas, atividades rotineiras (incluindo brincadeiras) e exploração de emoções, usando a metodologia qualitativa da observação participante. Os pontos principais da análise tinham como eixos temáticos a subjetividade da criança e do adolescente soropositivos, a vida institucional, $e$ as perspetivas de passado, presente e futuro.

Por outro lado, fiz observação participante dos espaços de relacionamento adulto-criança e realizei entrevistas formais e informais com os cuidadores. Da mesma forma, prestei especial atenção às instituições e suas conexões com a sociedade brasileira como um todo, participando, inclusive, das atividades do Fórum das ONG/Aids em São Paulo e da parceria ONG/Estado. Ressalto que a visão antropológica considera as estruturas sociais como partes fundamentais da subjetividade e da construção da experiência individual e coletiva (Kleinman, 1988). Portanto, esta visão não vê o problema da criança com Aids e seu desenvolvimento como fenômeno individual ou isolado.

A abordagem metodológica escolhida é consistente com novas teorias sobre a produção de pesquisa etnográfica, nas quais a intenção é juntar vários níveis da análise - múltiplos-sítios "multi-sited" (Marcus, 1998). Segundo Marcus, existem espaços fora da vida das pessoas e da "vida" dos sistemas sociais nos quais as pessoas vivem. Esses espaços informam as experiências do sujeito $e$ as relações ser-sistema. Na presente pesquisa, esses espaços representam o relacionamento adulto-criança, instituição-criança, instituição-idéias e noções da criança com Aids no Brasil de hoje. Assim, informa-se a experiência individual da criança com Aids com as respostas sociais das ONG/Aids e com as 
construções históricas e culturais fechando o círculo: experiência - resposta construção histórica e cultural - experiência. Por fim, para a análise, toma-se em conta não só os dados obtidos comcrianças, adolescentes e adultos, mas também dados das instituições, da construção histórica e cultural, e dos relacionamentos.

No presente artigo apresento dados selecionados do trabalho nas duas casas de apoio que representam tanto rotinas quanto conflitos. Enquanto os momentos de rotina estão em harmonia com as construções ao redor da criança com Aids, os momentos de conflito representam lutas individuais e coletivas rebatendo aquelas construções.

A primeira parte, "AS CASAS DE APOIO", trata do perfil das respostas sociais das ONG/AIDS, especificamente da casa de apoio e apresenta as experiências das crianças que vivem nelas. Na segunda parte, "ROTINAS E CONFLITOS", questiona-se o significado dos momentos de rotina e conflito introduzindo, na parte final, "IMAGENS", a análise das construções culturais e históricas da criança com AIDS e o significado da criança com Aids no Brasil de hoje.

\section{AS CASAS DE APOIO}

\section{O perfil das Casas de Apoio}

Em 1985 surgiu a primeira casa de apoio (Casa de Apoio Brenda Lee) como iniciativa das organizações não governamentais (ONGs) para cuidar e dar apoio a pessoas com Aids e sem recursos financeiros (Galvão, 2000). Com a aparição dos primeiros casos em crianças e as necessidades de moradia para os órfãos, foi inaugurado em 1987 o Centro de Convivência Infantil "Filhos de Oxum", em Taboão da Serra - SP. A inauguração desta casa, assim como a criação da maioria das ONGs/AIDS mais importantes, ocorre no período 1985-1989, considerado como "os anos heróicos das respostas não governamentais" (Galvão, 2000, p.45), nos quais as ONGs (formadas por militantes acadêmicos, grupos religiosos e partidos e/ou organizações políticas de esquerda) lutavam para garantir que os direitos dos pacientes fossem respeitados, principalmente o acesso às terapêuticas disponíveis (Galvão, 2000). Esta briga política gerou e estreitou, com o tempo, a parceria ONG-Estado e levou à melhoria nos programas DST-AIDS no Brasil e a sua atual liderança como programa de combate à Aids no mundo (Parker et al., 1999).

Nos anos de 1990 proliferaram as casas de apoio e outros projetos assistenciais aos soropositivos. Apesar da contínua fundação de novas casas de apoio - até hoje -, na visão dos analistas da epidemia e devido à melhoria da qualidade de vida das pessoas com AIDS, as casas de apoio deveriam, com o tempo, desaparecer para reinserir os soropositivos à sociedade e à família, em vez de isolá-los para oferecer assistência. Inclusive, algumas pessoas do movimento das ONGs apontam que a casa de apoio nunca deveria ter existido. Por outro lado, problemas de sustentabilidade e falta de recursos são cada vez maiores devido a uma saturação normal nos movimentos ONGs (Smith-Nonini, 2000), às mudanças nas características da epidemia, $e$ às novas necessidades em profissionalização e captação de recursos do "terceiro setor".

Cada casa de apoio funciona segundo seus critérios e crenças, tendo em comum, com as outras, as necessidades de cuidados em saúde e o seguimento 
${ }^{5}$ Oxum representa não só a maternidade, mas também o cuidado as crianças. Aflalo (1996) diz: "A filha de Oxum, é também boa mãe e defende os seus filhos como uma leoa, mas não faz, especialmente, exibição do seu amor materno." (p.75)

${ }^{6}$ Para uma visão detalhada do ritual do candomblé ver: Prandi (1991), Gonçalves da Silva (1995) e Aflalo (1996). Em resumo, o Pai de Santo

(babalorixá) é a figura principal do terreiro seguida pela mãe pequena ou pelo pai pequeno (segundo cargo em importância). $\mathrm{O}$ equede (a cozinheira) é uma sacerdotisa respeitada no terreiro que cuida dos orixás em transe e os elementos do culto, o ebômi (os antigos

administradores) é um um filho que já passou pelo rito de obrigação $e$ tem status de senioridade. das leis de abrigamento (com a figura de guarda como parâmetro legal). Saúde, então, marca o cotidiano das regras e funções da casa de apoio e se oferecem cursos aos funcionários nos cuidados específicos das crianças com Aids. Meu trabalho desenvolveu-se nas casas Filhos de Oxúm e Siloé. Uma descrição breve das mesmas pode esclarecer parte da experiência de vida das crianças e dos adolescentes em cada lugar.

\section{Casa de Apoio CCI - Centro de Convivência Infantil "Filhos de Oxum"}

Oxum é beleza, feminilidade, coquetaria, graça e sensualidade. É a dona do amor, mas também das águas dos rios. Adora perfumarse com lavanda, vetiver e outras ervas dos campos. Gosta de jóias douradas e de cobre, metal com que quer enfeitiçar o seu marido, Xangó. Protege a mulher grávida, a esposa contra as amantes, mas ela mesma é festeira, dançarina, conquistadora de homens (não importa se são casados). Está sempre alegre $e$ disposta a dançar. Foi a segunda esposa de Xangó, mas antes vivera com Ogum e Oxosse. É grande amiga de Yemanjá e de Exú, seu protetor. (Aflalo, 1996, p.73)

É uma casa de orientação religiosa do Candomblé (nações queto e angola). O Pai de Santo e presidente da ONG (Pai Laércio de Oxum) conta como a casa mudou de terreiro de Candomblé para casa de apoio. O cuidado das crianças demandava mais tempo dos colaboradores do candomblé e, por outro lado, "o ambiente festivo do candomblé, as iniciações e rituais podiam perturbar as crianças.” Assim, Laércio, por meio dos búzios, perguntou a Oxum ${ }^{5}$ o que deveria fazer, e conta como Oxum não somente aceitou fazer do terreiro uma casa de apoio, como também "falou que queria cuidar das crianças".

A estrutura da casa - casarão - como é chamado por todos os que a conhecem, incluindo trabalhadores, crianças e vizinhos, tem mudado várias vezes, tanto na estrutura física como nas pessoas que ali vivem e trabalham. Sobrevive principalmente de doações e alguma ajuda do Ministério da Saúde para manutenção. Não existe uma delimitação clara da parte administrativa da casa de apoio, já que Laércio, sua família biológica e adotiva, e os colaboradores mais próximos do Candomblé moram, trabalham e administram as casas (casa família e casa instituição).

Vários funcionários têm algum nexo com o candomblé, incluindo algumas babás, uma cozinheira e antigos administradores. A figura principal na casa é Obá, mãe pequena e mãe criadeira do terreiro, que veio ajudar Laércio por contatos com seu Pai de Santo em 1982 ou 1983 (já não lembra), e é quem, na virada de terreiro para casa de apoio, assumiu o cuidado das crianças como tarefa própria, convertendo-se na "mãe de criação" de todas as crianças ${ }^{6}$. Obá (seu nome do Candomblé e como é conhecida por todos) tem, por sua experiência, uma sabedoria infinita sobre o papel da maternidade: 
Cada criança é diferente, e cada uma precisa de uma atenção especial, de um carinho, cada uma é uma história. Eu os deixo em liberdade, não fico em cima deles (que não faz isto, que não faz aquilo...). A criança tem que experimentar, tem que aprender a se defender... Só às vezes que você precisa ter mão dura e dar um tapinha na bunda (risadas).

O número de crianças flutua entre 35 - 40 (entre soropositivos e filhos de portadores). Elas são cuidadas por duas babás por plantão. Entre as crianças $e$ os adolescentes existem várias hierarquias e escalas de poder percebidas quando as crianças falam dos outros, ou brigam com os outros. Os bonitos (preferidos) são aqueles com trato especial e podem ser grandes ou pequenos; são chamados filhinho de papai ou filhinho de mamãe (segundo sejam os protegidos de Laércio ou de Obá). Outra hierarquia baseia-se na antigüidade na casa e na forma como se fala do passado "ai!, o que que você está falando se você nem estava aqui”. Uma escala de poder depende do bom relacionamento com Laércio já que na casa também moram o filho legítimo e os dois filhos adotivos, e Laércio, segundo as crianças, "é quem manda aqui". Assim, a hierarquia estabelece-se do filho legítimo-filhos adotados-crianças preferidas (bonitos)-outras crianças. Existe, finalmente, uma hierarquia de poder físico que vai do mais forte ao mais fraco e que geralmente depende do tamanho e da idade.

\section{Casa de Apoio SILOÉ}

Duas passagens bíblicas foram significativas para minha reflexão. Uma é a passagem de Lc 13, 1-5, na qual são relatados fatos sangrentos e interpretados pelo povo como sendo castigos de Deus. Jesus, porém, dá uma interpretação bem diferente, dizendo que aquelas pessoas que morreram esmagadas pela Torre de Siloé não eram piores das que escaparam da catástrofe. Quis dizer que todos somos pecadores e precisamos de uma conversão contínua.

Outra passagem, do evangelho de Jo 9,1-11, relata a cura do cego de nascença. "Quem pecou, ele ou seus pais por ter nascido cego?", perguntam a Jesus. É a mesma pergunta feita ainda hoje por muitas pessoas diante de um doente de Aids. À pergunta dos discípulos Jesus respondeu: "Nem eles nem seus pais; isto aconteceu para que nele se manifestem as obras de Deus". As obras de Deus se manifestam na nossa conversão ao irmão doente, sem preconceitos e pré-julgamentos (Tomado do Boletim da casa Siloé, 2000).

Siloé é das primeiras casas de apoio católicas para crianças. Além das duas casas de apoio para crianças e uma para adultos, a paróquia tem outros centros não relacionados com a Aids - como uma creche e um centro esportivo - como parte dos serviços sociais que ela presta à comunidade. Financiada principalmente por doações da comunidade da paróquia no bairro Imirím, a instituição também se apóia no trabalho voluntário.

O Padre Valeriano, presidente das instituições e famoso por ter uma posição a favor da camisinha como forma de prevenção, tem sido criticado pelas alas conservadoras da igreja. A luta pela vida (como ele a chama) mostra simplesmente o lado de um esforço maior por dar sentido a uma evangelização real por meio da ação. Muitas das idéias são da corrente da Teologia da

${ }^{7}$ Siloé é um nome bíblico que significa "enviado".

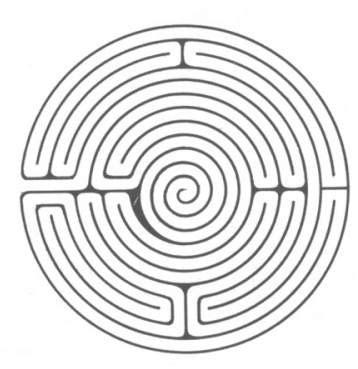


Libertação, considerada como a ala progressista da igreja (Boff et al., 1996). A casa Siloé fica fisicamente dentro da igreja, porém, tem uma entrada independente. Saindo da casa por um corredor encontram-se o escritório da tia Célia (diretora da casa) e a escolinha para fazer lição de casa. Além da tia Célia, existem quatro funcionárias - chamadas de tias, que trabalham das 7 às 22 horas para cuidar das 14 crianças - e os voluntários da comunidade religiosa, que têm diversas funções, geralmente com duas funcionárias por plantão. Existem também voluntários para as consultas médicas, ou seja, acompanhantes para ficar no hospital com a criança, e motoristas.

A rotina semanal gira ao redor da escola, das brincadeiras e do relacionamento com as quatro funcionárias e a tia Célia. Aos sábados $e$ domingos o Padre almoça com as crianças no refeitório da casa. Nessas ocasiões o Padre se inteira dos últimos acontecimentos e, geralmente, a troca afetiva por favores começa com uma aproximação física, ou puxar a barba, pegar pelo braço e depois "Oh Padre, sabe de..."

Os castigos vêm da funcionária do plantão, quando se faz necessário. É a tia Célia quem define as ordens e, em casos extremos, recorre-se à máxima autoridade - o Padre. Mas o Padre "é dez, ele não fica bravo..."

\section{A criança HIV positiva na casa de apoio} Imagine por um instante...

você tem quatro anos de idade. Sua mãe morreu quando você tinha um ano e deixou-o aos cuidados de seu pai. Logo depois, seu pai entregou você aos cuidados de seu avô e não voltou mais. Seu avô gosta de você, é carinhoso; mas a companheira dele, que não é sua avó, diz que você é "terrível, desobediente, se recusa a obedecer a ordens, e que ela bate se precisar." Você tem medo dela. Ela bate mesmo, você não entende quando é preciso ou não. Além disso, ela também comenta que você "só tem cara de santo, que não parece doente e é impossível lidar com você."

Quando o conheci você tinha aqueles quatro anos e já estava na casa de apoio: cabelo loiro e cacheado, magro, de olhos tristes com halos roxos, como quando alguém está com gripe. Tinha também um algodão cobrindo seu ouvido, vestia shorts, tênis novos e camiseta regata, era um dia de sol. Quando o vi, no meio do playground de sua nova casa, você me cumprimentou, estendendo a mão e dizendo "oi, boa tarde". Depois de conhecêlo melhor, não o reconheço como aquela criança descrita pela mulher de seu avô. Sua nova casa é bem diferente. Tem várias senhoras que dão comida e banho. Engraçado, todo mundo sabe seu nome, mas alguns indicam você com o dedo e falam "esse é o novo". Também tem muitas crianças pequenas e grandes. Em sua nova casa há outra senhora que todo mundo chama de mãe. Ela tomou conta de você durante os primeiros meses na casa, deu comida, olhava você quando dormia num berço ao lado da cama dela e fazia muitos carinhos. Você começa a chamá-la de mãe. As outras crianças brincam e brigam com você o tempo todo. Você pode brincar no playground e no salão. Depois de alguns dias conhece melhor as outras crianças e tem amigos. A mãe já não fica a seu lado o tempo todo e você tem que disputá-la com os outros.

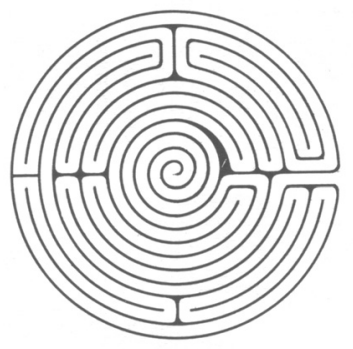
Às vezes, vêm tios e tias para brincar. Você se diverte e tem colo, depois eles vão embora. Às vezes, você apanha das outras crianças, dos maiores que batem forte, mas ainda não apanhou das tias. Você vai ao médico uma vez por mês, às vezes mais. Vai começar a freqüentar a escolinha, ganhar ovos de páscoa, vai chorar quando não tiver carrinho para brincar. Quando crescer, vai achar 'chatice' a forma como alguns adultos o tratam. 
Das múltiplas opções de casa de apoio, Bruno (o nome fictício desta criança) terminou nesta. A história poderia ter sido diferente e ainda pode mudar. $\mathrm{O}$ acaso, descrito como o imprevisível ou aquilo que não podemos explicar racionalmente, determina, nas crianças HIV positivas, como no caso de Bruno, as opções de vida. Por que foi Bruno e não outra criança a infectada pelo HIV? $\mathrm{O}$ acaso, porém, tem determinantes importantes. No caso do HIV, o nascimento de uma criança HIV positiva e as respostas que recebe em caso de morte dos pais, depende das diferentes estruturas familiares, determinadas por uma multiplicidade de fatores sociais e econômicos.

$\mathrm{O}$ acaso determinou que o Bruno nascesse de um casal contaminado, mas os determinantes sociais e históricos dessa contaminação são pobreza e violência estrutural (Farmer, 1999). O acaso determinou que Bruno se infectasse de sua mãe (tinha também possibilidades de não se infectar); uma baixa qualidade no atendimento das gestantes, um pré-natal inadequado $e$ a falta de controle terapêutico inclinaram a balança para que Bruno se infectasse. $O$ acaso influencia, também, a chegada de Bruno nesta casa de apoio e não em outra. Poder-se-ia pensar que os cuidados e as condições das casas de apoio para crianças HIV positivas são homogêneos ou que não teria tido muita importância qual casa de apoio tivesse abrigado Bruno. Não obstante, as casas de apoio apresentam, do mesmo modo que as famílias, diversidades marcantes.

Assim, quando uma criança nasce para uma casa de apoio, ela pode nascer para uma casa que se considera instituição ou casa; na cidade ou no interior; católico, evangélico, espírita, do candomblé, ou sem prática religiosa. Pode nascer para uma casa com poucas crianças ou outras com mais de cem; talvez a criança possa ser adotada e morar com uma família de novo. Há casas com idéias naturistas de alimentação e cuidados de saúde. Há outras nas quais as crianças cuidam de suas coisas e outras onde tudo é destruído. Casas que têm colégio privado de primeira qualidade ou escola pública; onde na quarta série, alguns têm classes de inglês, mas outros não conseguem ler. Algumas têm viagens para o exterior e outras não têm passeios. Há casas que valorizam a participação em grupos de crianças e jovens, mas em outras as crianças e adolescentes são escondidos da sociedade para que eles "não sofram com o preconceito". Inclusive, é evidente que em algumas casas os cuidados são melhores que em outras, e os segredos (por exemplo na forma como se fala ou não da AIDS ou do passado das famílias) são maiores que em outras. Existem casas preocupadas com temas como o desenvolvimento infantil, mas também outras preocupadas só com a sobrevida. Muitas dessas diferenças dependem da filosofia e crenças dos administradores e responsáveis, da falta de critérios unificados para o cuidado fora das esferas de saúde e do controle legal, e das diferenças econômicas que representam não só a diversidade do Brasil, mas também suas desigualdades sociais. O futuro das crianças é, mais uma vez, determinado pelo fato de ter ou não um vírus no sangue, das orientações políticas e condições econômicas das respostas sociais (casas de apoio), das políticas perante os cuidados e o acaso ${ }^{8}$.

Em minha pesquisa percebi diferenças marcantes das crianças e dos adolescentes com quem trabalhava, que tinham a ver não com a estrutura de cada instituição que influenciava, de forma importante, o seu desenvolvimento individual e social. Este fato era consistente com múltiplas pesquisas em

\author{
${ }^{8}$ Em uma análise \\ comparativa mais \\ ampla, tentei comparar \\ a perspectiva de vida $e$ \\ futuro das crianças HIV \\ positivas com as \\ crianças em situação de \\ rua (Abadía-Barrero, \\ 2000). Em outro \\ trabalho, tentei \\ mostrar um panorama \\ mais complexo das \\ possibilidades de vida $e$ \\ futuro segundo o tipo \\ de instituição na qual a \\ criança é abrigada \\ (Abadía-Barrero, 2002).
}


desenvolvimento infantil das áreas de Psicologia Social, Educação e trabalhos comparativos de desenvolvimento infantil em várias culturas (ver, por exemplo, Whiting \& Edwards, 1988). Para entender as construções ao redor da criança com Aids, meu interesse centra-se nas semelhanças e não nas diferenças entre as casas, nos determinantes institucionais e culturais que juntavam as experiências de vida dessas pessoas.

\section{ROTINAS E CONFLITOS}

White (1981) explica como a criança na modernidade se desenvolve em três mundos diferentes: o mundo familiar, o mundo profissional e o mundo comercial. No caso das crianças com Aids em casas de apoio, vemos que, apesar de compartilhar estas características da modernidade, também têm particularidades. O mundo familiar é mudado pelo mundo institucional $e$, para alguns, pelo mundo da família e da casa de apoio. Ao mundo profissional, descrito por White principalmente como o mundo da escola, temos que somar o mundo do hospital, e aos profissionais em Educação, os da área da Saúde. O mundo comercial, por outro lado, não apresenta diferenças para as crianças em casas de apoio comparadas com outras crianças na modernidade brasileira.

\section{As Rotinas...}

Tanto no CCI quanto na Siloé, a condição médica, ou seja, ter uma infecção crônica, implica que crianças e adolescentes tenham como parte das rotinas as visitas ao hospital, os médicos e os medicamentos. Além da escola, das brincadeiras, dos namoros, da TV, da rua, da comida, dos amigos, dos voluntários e funcionários, a relação com as esferas de saúde torna-se um referencial importante para elas.

Outra rotina é no mundo comercial, em que as conexões se baseiam, principalmente, na criança como consumidor de produtos. O consumo, no desenvolvimento das crianças, é vivenciado no plano das brincadeiras, na forma de vestir, na música e na TV, com seus padrões de êxito, beleza, relações de gênero e sexualidade. Cada vez que a sociedade produz uma nova categoria, como a categoria criança, o mundo comercial se volta para promover novas necessidades de consumo próprias daquela categoria $e$, simultaneamente, satisfazer aquelas necessidades mediante a oferta de produtos. As crianças com Aids não escapam disso.

Os dois casos, CCI e Siloé, fazem parte de um projeto maior e não são, portanto, uma realização em si. O CCI, como casa de apoio, faz parte do projeto familia; a Siloé, do projeto da igreja. A visão religiosa é fundamental. Mesmo que os administradores insistam na independência da parte religiosa do funcionamento da casa, nota-se que as idéias de criação, as atividades permitidas e a forma como os adultos se relacionam com as crianças, fazem parte da construção religiosa individual e institucional. Se no CCI existe menos controle adulto e mais libertade, na Siloé existe ênfase maior na escola/educação e no "bom comportamento". Por fim, o nível de instrução e capacitação do pessoal marca outras diferenças. No CCI o ambiente é mais familiar e na Siloé mais institucional; na Siloé existem mais possibilidades 
para trabalhar aspectos relacionados à AIDS, enquanto no CCI esses aspectos são mais silenciados pelos adultos e, como conseqüência, pelas crianças e pelos adolescentes. As hierarquias, mais marcadas no CCI, são característica da construção social de camadas populares em que estruturas de poder fazem parte do cotidiano (Duarte, 1986).

O financiamento via doações e projetos e a chegada de novas crianças na medida em que outras crianças voltam com as familias ou são adotadas, são outras similitudes entre as casas. Outros aspectos sociais marcam também semelhanças importantes. Nas horas de visita, várias pessoas chegam "para brincar" (com curiosidade de saber como são as crianças ou com desejos de se sentir bem visitando os enfermos) e surpreendem-se em ver como as crianças são bonitinhas. Os funcionários da Siloé incomodam-se com a forma como as visitas se relacionam com as crianças "que falsidade, os tratam como se fossem macacos." No CCI se fala "nada podemos fazer, vivemos da caridade, temos que aceitar as visitas."

Existe, então, um imaginário geral da criança com Aids (carente, órfã, doente e coitada). Por outro lado, explorar a imagem da criança como ser necessitado gera na caridade aportes econômicos e trabalho voluntário importante para a sustentabilidade das casas. Nesta duplicidade, na qual se aceita a visão de carência para o exterior, mas se quer dar uma noção de normalidade e rigor no interior da casa, as crianças aprendem a viver e tirar vantagem, quando possível, de uma idéia ou da outra, dependendo da situação mais conveniente.

Quem trabalha diretamente com as crianças e os adolescentes observa que suas necessidades vão além dos episódicos e intensos momentos de carinho dos visitantes, vistos como negativos (dependendo do visitante). Na ausência do núcleo familiar, as satisfações das necessidades de orientação e discussão de problemas na casa de apoio dependem do adulto do turno. Diretor, coordenador, funcionário, voluntário, profissional também têm perspectivas diferentes entre si. Ou seja, a confusão que crianças e adolescentes vêem nos adultos limita-se não somente ao tema da Aids (que é falado e discutido ou não, segundo a visão do adulto que esteja por perto), como também a conselhos, tarefas, orientações, castigos, visão do mundo e padrões de criação.

O conflito: "Eles cresceram, ninguém estava preparado para isso"

\footnotetext{
Antes era muito difícil, César, o tempo todo tínhamos alguma criança internada. E as crianças não eram assim bonitinhas como você as vê agora, eram doentes, mas doentes mesmo. Parecíamos loucos, que uma vomitando, que a outra com diarréia, que a infecção de ouvido, que as feridas na pele, que a febre... Parecia que a gente não podia pensar em mais nada que em crianças doentes...

Também, era horrível quando eles morriam. Uma vez tínhamos 12 internados, voltávamos com 11 , internávamos 3 voltávamos com 2 ... Ficávamos pensando qual seria o seguinte.
}

Essa fala de Obá indica que a situação de saúde tem melhorado, felizmente. Por um lado, o peso histórico da Aids nessa casa (CCI) faz com que os adultos 
${ }^{9}$ A revelação da AIDS é um processo difícil pelas associações com estigma, discriminação, culpa materna, $e$ à idéia de que a criança vai sofrer com essa revelação. Mesmo que estas dificuldades tenham sido analisadas na relação pais-filhos, ela é vivenciada também nas casas de apoio. façam uma associação forte da Aids com sofrimento que não querem passar para as crianças, o que pode ajudar a compreender em parte o segredo em relação à palavra Aids $e$ as dificuldades para revelar e lidar com o diagnóstico ${ }^{9}$. Existem novos problemas para os quais ninguém estava preparado quando as crianças começaram a crescer. Em outros comentários, Obá reconhece que os cuidados das crianças pequenas - às quais dedica mais tempo - são diferentes dos cuidados de crianças maiores. Segundo a concepção da maioria na casa, não só a criança pequena precisa de cuidados mais simples - o banho, a comida, as brincadeiras e "ficar de olho", mas quando a criança cresce começa a dar problema. Na Siloé, do mesmo modo, sabe-se que com os adolescentes "começam os problemas." Parece que cuidar de criança pequena e de criança doente, mesmo requerendo maior esforço físico, é mais fácil. A surpresa dos problemas que as crianças trouxeram quando cresceram faz pensar que se esperava que todas iam morrer. Quando ocorre o sucesso terapêutico na Aids, a concepção de casas de apoio precisa ser modificada, para poder lidar com o advento dos adolescentes, o que não aconteceu.

No abrigo Moóca (abrigo estadual do SOS criança para meninos em situação de rua) encontra-se Maurício, um adolescente de 12 anos, ameaçado por uma gang que traficava drogas na favela onde morava. Sua mãe decide abrigá-lo porque teme pela sua vida. Além de precisar de abrigo, Maurício é HIV positivo. Procuramos encaminhá-lo para uma casa de apoio para crianças/adolescentes HIV positivos. Nossa busca (ligando para mais de 15 casas no Estado de São Paulo) foi infrutífera, já que a quase totalidade das casas têm limites de idade, segundo os estatutos desenhados pelos diretores. Isto sem contar que, além do problema da idade, pergunta-se se a criança é bem comportada, caso contrário a vaga não é oferecida.

Poder-se-ia pensar que "o problema" de ter crianças que viraram ou estão virando adolescentes fosse um problema particular das casas mais antigas que começaram quando a epidemia estava ainda ligada à morte nos primeiros anos de vida - mas a experiência com Maurício mostra que casas novas e velhas têm o mesmo ideário ao redor do tipo de criança com Aids de que se quer cuidar, isto é, criança pequena, doente e que não dê problemas. Ao trabalhar somente com este ideário e negar o passo à adolescência, juventude e ao homem e à mulher adultos, o crescimento vira problema $e$ parece que se pensa que as casas sempre vão ter ou ser para crianças.

$\mathrm{Na}$ análise social mais ampla, a pergunta seria: qual o valor que os adultos dão às crianças soropositivas e porque existe a tendência ao senso de propriedade sobre crianças e desejos de "ficar" com certo tipo de crianças ou não, como no caso de Mauricio? O que têm as crianças doentes que perdem quando viram adolescentes saudáveis, dificultando a vida dos cuidadores $e$, portanto, passam de "não dar problema" a "ser o problema"?

\section{IMAGENS}

Criança, um invento cultural:

William Kessen escreveu em 1979 um artigo chamado "A criança americana $e$ outras invenções culturais". Nesse artigo, o autor lembra como o conceito de criança, o mundo da criança $e$ as transformações da criança são 
redefinidos, principalmente nos tempos modernos. Lembra que Ariès já tinha apontado, em 1962, que a noção de criança e infância se transformam historicamente ${ }^{10}$. Essa transformação, aponta Kessen, não se deve ao conhecimento incompleto da ciência, mas sim a uma invenção cultural, na qual concebemos a criança como sozinha, como ser em desenvolvimento completamente individual, ou seja, sem reconhecer que o desenvolvimento é, afinal, uma construção social (Kessen, 1979).

Estas idéias foram esclarecedoras para entender a forma como a sociedade moderna se tinha voltado ao entendimento da criança como categoria referencial de desenvolvimento, sem passar pelas esferas sociais. É por isso que se tem desenvolvido atividades para a criança, elementos de consumo para crianças, sentimentos de crianças, livros de crianças, profissionais para crianças, e até novas necessidades das crianças. Algumas dessas invenções sociais são necessárias e formam parte do desenvolvimento do mundo moderno (White, 1981); todavia, este desenvolvimento inventa, num círculo vicioso, aquelas necessidades e determina as características que as crianças devem ter para se encaixar no mundo moderno. Não é de surpreender que Liljeström (1981), e como resposta às idéias de Kessen, pense a criança circulando em esferas públicas, comerciais e familiares.

As análises baseiam-se nas idéias particulares de infância de cada época $e$ na medida em que se criam novas idéias e novas necessidades, novas análises são geradas. Note-se, por exemplo, a dificuldade de falar de crianças com Aids quando já se tem adolescentes com características próprias - características e necessidades também inventadas. Assim, Kessen observa que foram necessárias novas invenções, como o jovem, para diferenciá-lo do adolescente, os pré-escolares dos escolares e, mais recentemente, a onda teen e os pré-adolescentes. Para ele, estas novas idéias acontecem pela necessidade de novas categorizações e objetos de estudo, característica das sociedades ocidentais, da ciência e das sociedades de consumo. A concepção moderna de criança volta o todo à criança como categoria auto-suficiente e independente. Assim, este "mundo criança" perde suas conexões $e$ determinantes sociais.

O desenvolvimento da criança: o melhor invento para uma modernidade em paz

A situação da criança atual é, no meu modo de ver, uma situação extrema na qual ela é ignorada como ser social em desenvolvimento (o mundo criança é independente individual e auto-suficiente) e, portanto, a importância de sua existência não tem como referente o adulto do futuro, mas sim as necessidades satisfeitas no presente. O objeto criança da modernidade não é o ser em desenvolvimento, mas sim seu desenvolvimento. Passou-se de ignorar a criança quando se pensava que sua existencia só fazia sentido dependendo do homem que se geraria no futuro (o produto da criação) sem reconhecer características e necessidades específicas do desenvolvimento antes de chegar no adulto - para uma outra forma de ignorá-la caracterizando as diferentes etapas nas quais a criança se encontra, num momento determinado. Ou seja, temos listado as necessidades a cumprir
${ }^{10}$ Passou-se de ignorar a criança a pensá-la como um adulto em miniatura no século XIII, ou como um anjo ou como um elemento da paisagem social em relação com os outros, até caracterizá-la como símbolo de beleza, força ou ternura, segundo pinturas de diferentes séculos. A criança tornou-se a idade privilegiada, passando pelas idéias do "jovem" do século XVII, para criança do século XIX, para adolescência no século XX (Ariès, 1962). 
segundo cada etapa (bebê, criança, pré-escolar, escolar, pré-adolescentes, adolescente, teen, jovem etc.) mas não sabemos como a criança faz parte dessas etapas e negocia com os diferentes ambientes seu desenvolvimento individual $e$ social. Inclusive, parece impossível que a criança (ou adultos e velhos) transite por várias dessas etapas simultaneamente sem ser patologizado; se um adulto for resgatar sua dimensão criança, falar-se-ia de regressões ou comportamentos infantis. Por outro lado, o aceitar a criança e seu desenvolvimento como ligados diretamente aos determinantes sociais obrigaria a pensar em processos e não etapas/categorias, como a modernidade do ocidente nos faz ver.

Nas casas, o "problema" de as crianças terem crescido dá-se porque quando ela (pertencente a uma categoria específica) cresce, muda de categoria $e$ desestrutura um esquema criado para sua categoria inicial. O modelo ocidental ensina a pensar e compreender os problemas do mundo segundo categorias $e$ não a pensar que cada problema faz parte de um processo. Ao pensar em categorias, negou-se o desenvolvimento, e o crescimento virou problema. Inclusive lingüisticamente percebe-se a idéia de categorização quando se fala "as crianças cresceram" e não "as crianças estão se desenvolvendo". Passa-se longe de perceber que todos nós somos seres em desenvolvimento, e não só as crianças, evidenciando outra idéia moderna, a de que crianças e adultos pertencem a dois mundos diferentes.

\section{Criança no Brasil e criança soropositiva, para terminar...}

O Brasil pode ter, talvez, uma das trajetórias mais importantes na ligação de criança com sofrimento. A escravidão, o trabalho infantil, a miséria, a desnutrição, as altas taxas de morbidade e mortalidade infantil, $e$ as crianças de rua são referenciais importantes quando se fala da criança brasileira no mundo atual (Rizzini, 1993a; Rizzini, 1993b). Porém, as origens das ameaças que as crianças brasileiras enfrentam, fazem parte do processo histórico que as liga às desigualdades sociais baseadas em novas $e$ velhas estruturas econômicas $e$ às diferenças de raça, religião, gênero, região e classe social, desde a época colonial ${ }^{11}$.

Não pretendo percorrer a extensa literatura do papel da criança e da família no Brasil, mas considero importante citar alguns trabalhos que esclarecem a discussão das imagens das crianças brasileiras com AIDS. A alta mortalidade da AIDS (antes da terapia antiretroviral) colocou a vida das crianças e a expectativa de morte no mesmo plano da morte infantil como causa da pobreza extrema.

${ }^{11}$ Ver Freyre, 1977, para uma visão histórica da formação da familia brasileira.
Nestes casos, a morte da criança tem sido descrita como parte da vida cotidiana; mães, inclusive, enfrentam as múltiplas perdas dos filhos como necessárias para a sobrevida de outros (Scheper-Hughes, 1992). A sobrevida dos filhos tem, para as camadas mais pobres, um significado especial econômico, além da gratidão e troca afetiva, que pode significar cuidados para os pais na velhice (Fonseca, 1995). No caso da Aids, isto não acontece, já que o cuidado das crianças fica no plano da gratidão e do "cuidar dos filhos dos outros." Porém, a chegada da criança com Aids na casa de apoio pode ser pensada como uma etapa a mais dentro da "circulação das crianças", nas quais famílias de camadas populares utilizam lares substitutos por períodos variados para ajudar na criação dos filhos (Fonseca, 1995). É comum, então, que uma criança tenha 
várias mães e pais em sua vida, porém, a mãe biológica sempre terá um papel principal, como acontece quando as crianças com AIDS voltam felizes a viver com os pais que, além de não terem recursos financeiros, podem ter problemas de violência e maus tratos.

Estudos antropológicos mostram como os cuidados, as estruturas familiares e o papel da criança na família têm uma moralidade própria que se estabelece segundo as dificuldades econômicas das famílias, nas quais a circulação da criança é uma opção moralmente aceitável (Sarti, 1996). Para Sarti, a pobreza é uma categoria relativa na qual a criança, mesmo que desejada como realização feminina e realização familiar, deve ser obediente $e$ submeter-se a estruturas hierárquicas de poder - como visto nas casas de apoio quando os adolescentes saudáveis viram um problema pela ameaça que representam às estruturas estabelecidas ${ }^{12}$.

No caso das crianças com Aids em casas de apoio, a troca afetiva parece fundamental como parte das idéias ao redor da criança. Troca afetiva não só pelo fato de cuidar da criança e ter uma relação emocional de mãe-pai substituto e filho-filha substituto, como também pela retribuição moral (idéia construída junto à religiosidade), pelo que há de bom em sua atitude. Esta bondade permite desculpar, justificar e inclusive aceitar legalmente os erros. Note-se, novamente, que o controle das casas baseia-se exclusivamente em saúde e abrigamento legal, sem ter em conta outros aspectos das necessidades das crianças e adolescentes em desenvolvimento. Se, por um lado, mais controle e apoio governamental são indispensáveis - adicionando saberes técnicos fora da saúde hospitalar e do sistema legal -, por outro lado, nas casas de apoio, o fato de se assumir como instituição, de se profissionalizar e de se ter uma remuneração adequada para os funcionários, poderia modificar as idéias de caridade associadas ao cuidado das crianças. Passar-se-ia a um plano de contrato e responsabilidade no trabalho, com o qual se conseguiria ter uma visão diferente perante a criação das crianças $e$ adolescentes. Infelizmente, a maioria das casas ainda insiste em ser casa no trabalho voluntário e baixos salários, misturando noções de caridade e responsabilidade, sem parâmetros unificados de como satisfazer as necessidades de crianças e adolescentes.

A criança soropositiva no Brasil circula inicialmente na família, ou entre vizinhos, até chegar às instituições. A modernidade também começou a limitar a liberdade de circulação da criança, fazendo-a passar por um processo legal de abrigamento, via juizado (claro que os direitos da criança são outro invento moderno).

As ligações da epidemia com um passado de limitação fisica, doença $e$ certeza de morte, ajudaram a criar uma categoria extrema de criança com Aids, como estado inamovível, apresentando problemas quando se deram a saúde e a sobrevida. A sociedade tem criado uma fantasia ao redor da criança com Aids. Por um lado, a construção histórica ocidental, no geral, faz ver a criança como sujeito inocente, assexuado, carente e necessitado de cuidados $e$ carinhos, que não deveria sofrer. Por outro lado, a Aids ou a doença adiciona o olhar de "pesar" com o qual a sociedade se relaciona com as crianças. Outras crianças no Brasil têm sofrido devido às injustiças sociais, porém, a categoria doença, e neste caso a Aids (com o imaginário de vítima inocente),

\footnotetext{
${ }_{12}$ Contudo, o problema na pesquisa de Sarti é que, mesmo sendo categoria relativa, a pobreza é analisada como característica essencial do grupo social e não como fator externo que limita o livre exercício da essência das pessoas. Ver também o trabalho de Duarte (1986) para uma análise da construção cultural das classes trabalhadoras em relação aos "nervos" a às dificuldades econômicas.
} 
funcionou para objetivar, ainda mais, aquela categoria extrema "doençainfância-sofrimento-vítima."

As crianças com Aids foram imaginadas como o exemplo máximo da categoria infância-sofrimento, a qual, associada com piedade e pesar, simboliza a combinação perfeita para a resposta individual e moralmente aceita de caridade. À medida que a criança com Aids deixa de ser doente e deixa de ser criança, vira o adolescente saudável, que ameaça tão acalentadas categorias da modernidade.

\section{Referências}

ABADÍA-BARRERO, C. Ainda bem que tenho AIDS. Rio de Janeiro, POSTER. Fórum, 2000. Rio de Janeiro, 2000.

ABADÍA-BARRERO, C. GROWING UP IN A WORLD WITH AIDS: Social advantages of having AIDS in Brazil. AIDS Care (In Press - 2002).

AFLALO, F. Candomblé: uma visão do mundo. São Paulo: Mandarim, 1996.

ARIÈS, P. Centuries of childhood: a social history of family life. New York: Alfred A. Knopf, 1962.

BASTOS, F. I., SZWARCWALD, C. L. AIDS and pauperization: principal concepts and empirical evidence. Rep. Public Health, v.16, sup. 1, p. 65-76, 2000.

BOFF, L., RAMOS REGIDOR, J., BOFF, C. A Teologia da Libertação: balanço e perspectivas. Roma: Editora Ática, 1996.

DUARTE, L.F. Da vida nervosa nas classes trabalhadoras urbanas. Rio de Janeiro: CNPq, 1986.

FARMER, P. Infections and inequalities: the modern plagues. Berkeley and Los Angeles: University of California Press, 1999.

FARMER, P., CONNORS, M. et al. (Eds.) Women, poverty and AIDS: sex, drugs and structural violence. Monroe: Common Courage Press, 1996.

FONSECA, C. Caminhos da adoção. São Paulo: Cortez Editora, 1995.

FREYRE, G. Casa Grande y Senzala: introducción a la historia de la sociedade patriarcal en el Brasil. Caracas: Biblioteca Ayacucho, 1977.

GALVÃO, J. AIDS no Brasil: agenda de construção de uma epidemia. São Paulo, Rio de Janeiro: Editora 34, ABIA, 2000.

GONÇALVES DA SILVA, V. Orixás da Metrópolis. Petrópolis: Vozes, 1995.

KESSEN, W. The american child and other cultural inventions. Am. Psychol., v.34, p. 815-820, 1979.

KLEINMAN, A. The illness narratives. United States of America: Basic Books Inc. 284, 1988.

LILJESTRÖM, R. The public child, the commercial child, and our child. In: KESSEL, F., SIEGEL, A. W. The child and other cultural inventions. New York: Praeger Publishers, 1981. p.124-52.

MARCUS, G. Ethnography through thick \& thin. Princeton: Princeton University Press, 1998.

PARKER, R., GALVÃO, J., SECRON BESSA, M. Saúde, desenvolvimento e política: respostas frente à AIDS no Brasil. São Paulo, Rio de Janeiro: Editora 34, ABIA, 1999.

PARKER, R., ROCHEL, D. C. J. K. Poverty and HIV/AIDS: anthropological and sociological aspects. Rep. Public Health, v. 16, Sup. 1, p. 89-102, 2000.

PRANDI, R. Os candomblés de São Paulo. São Paulo: HUCITEC, 1991.

RIZZINI, I. A assistência à criança no Brasil: uma análise de sua construção. Rio de Janeiro: Editora Universitária Santa Úrsula, 1993a.

RIZZINI, I. A criança no Brasil hoje: desafio para o terceiro milênio. Rio de Janeiro: Editora Universitária Santa Úrsula, 1993b.

SARTI, C.A. A família como espelho: um estudo sobre a moral dos pobres. Campinas: Autores Associados, 1996.

SCHEPER-HUGHES, N. Death without weeping: the violence of everyday life in Brazil. Berkeley: 
ABADÍA-BARRERO, C. E.

University of California Press, 1992.

SILOÉ, C. Boletim Siloé. São Paulo: Casa Siloé, 2000.

SMITH-NONINI, S. The smoke and mirrors of health reform in El Salvador: Community Health NGOs and the not-so-neoliberal state. In: KIM, J., MILLEN, J., Irwin, A., Gershman, J. (Eds.) Dying for growth. Monroe: Common Courage Press, 2000. p.359-81.

WHITE, S. Psychology as a moral science. In: KESSEL, F., SIEGEL, A. W. The child and other cultural inventions. New York: Praeger Publishers, 1981. p.

WHITING, B. B., EDWARDS, C. P. Children of different worlds. The formation of social behavior. Cambridge: Harvard University Press, 1988.
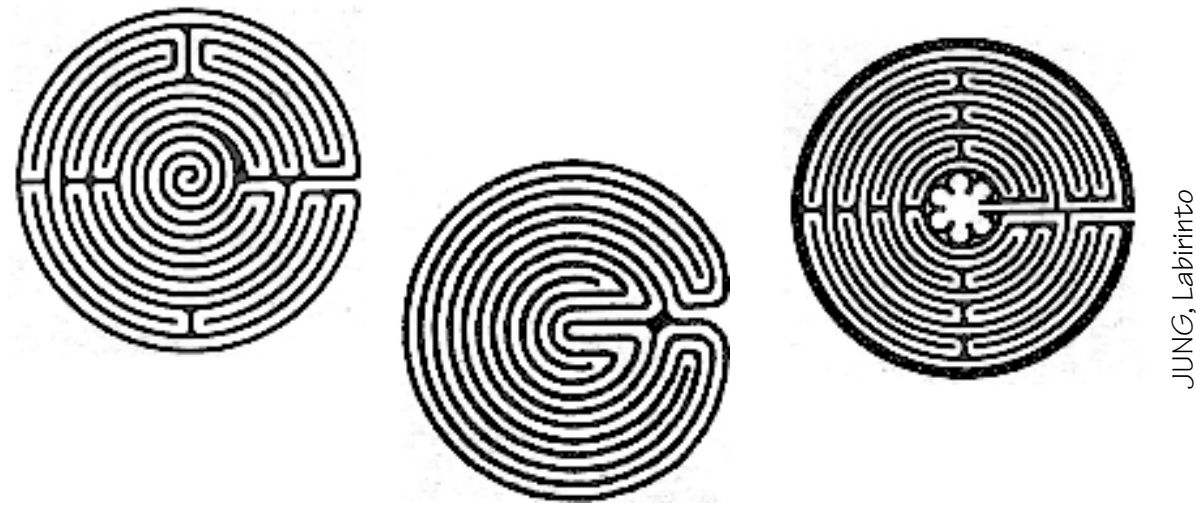

ABADÍA-BARRERO, C. E. Niños que viven con VIH Y Casas de Apoyo en San Pablo: Cultura, experiencias y contexto domiciliar, Interface - Comunic, Saúde, Educ, v.6, n.11, p.5570, 2002.

Este artículo, basado en una investigación del área de Antropología Médica, pretende analizar algunos factores culturales que influyen en el desarrollo de niños y adolescentes que viven con SIDA en casas de apoyo. Existen similitudes y diferencias en los patrones de crianza de cada institución y, en consecuencia, en el desarrollo individual y social de los niños y los adolescentes. Una similitud expresiva es, sin embargo, que la mejoría en la calidad de vida y el aumento en la sobrevida (con muchos niños que se convierten en adolescentes) parecen haberse convertido en un problema para los adultos que los cuidan. Intento explicar como este problema se debe, en gran medida, a las ideas y al imaginario de lo que el niño con SIDA en el Brasil representa. Estas ideas son culturalmente construidas y están en sincronía con las categorías y discusiones modernas sobre niñez, desarrollo y respuestas sociales moralmente aceptables. El desarrollo de los niños y adolescentes que viven con VIH/SIDA cuestiona esas categorías amenazando, inclusive, los patrones de crianza establecidos por los adultos y las estructuras de las instituciones.

PALABRAS CLAVE: Niño y adolescente, VIH, casas de apoyo, cultura. 